\title{
MATERIALISMO HISTÓRICO E DEFINIÇÃO DE PSÍQUICO
}

Fernando G. Castro

Universidade Federal de Santa Catarina, Florianópolis, Brasil

RESUMO: No Brasil, autores de referência no campo da Saúde Mental e Trabalho vêm trabalhando no sentido de demarcar o objeto da Psicologia com base no materialismo histórico, em função de uma série de insuficiências teóricas detectadas na ciência psicológica. Este artigo analisa as fontes teóricas da definição de psíquico utilizada por Codo e colaboradores baseados no materialismo histórico em seus estudos sobre o sofrimento psíquico e trabalho, identifica suas deficiências teóricas e mostra as razões pelas quais os autores não conseguiram superar a noção de psíquico psicanalítica como se propuseram. Indica, por fim, uma hipótese teórica baseada na definição de práxis, para um avanço na compreensão das relações entre sofrimento psíquico e trabalho que não se reporte a posições metafísicas como fizeram os autores analisados.

PALAVRAS-CHAVE: materialismo histórico; definição de psíquico; práxis.

\section{HISTORICAL MATERIALISM AND DEFINITION OF PSYCHIC}

\begin{abstract}
In Brazil, authors of reference in the field of Mental Health and Labour have been working to demarcate the object of Psychology based on historical materialism, according to a series of theoretical shortcomings detected in psychological science. This paper examines the theoretical functions of the definition of psychic used by Codo and collaborators, based on historical materialism in their studies about psychic suffering and work, and mean to identify its theoretical shortcomings, and show the reasons why the authors failed to overcome the notion of psychic psychotherapy as proposed. Finally, indicates a theoretical hypothesis based on the definition of praxis for a breakthrough in the understanding of the relationship between psychic suffering and work that does not carry the metaphysical positions as did the authors analyzed.
\end{abstract}

KEYWORDS: historical materialism, definition of psychic; praxis.

\section{Introdução}

No Brasil, autores de referência no campo da Saúde Mental e Trabalho vêm trabalhando no sentido de demarcar o objeto da Psicologia com base no materialismo histórico, em função de uma série de insuficiências detectadas na ciência psicológica que impedem o avanço do conhecimento das relações entre trabalho e sofrimento psíquico, conforme SeligmannSilva (1996), Lima (2002), Codo, Sampaio e Hitomi (1992) sustentam. Este é caso de Wanderley Codo e um conjunto de colaboradores que, fazendo eco às palavras de Seligmann-Silva, afirmam: "é mentira que a crise econômica de 1929 tenha gerado suicídios, gerou algum mecanismo psicológico que, por sua vez, gerou o suicídio" (Codo, Sampaio, \& Hitomi, 1992, p. 23). E, nesse sentido, estes autores vão em busca desses mecanismos psicológicos, ou seja, em busca do objeto da psicologia ao amparo do materialismo histórico, para, assim, superar a situação teórica e prática, na qual "as investigações das relações entre saúde mental e trabalho não têm revelado sobre a questão nada mais que rápidas iluminações. Sabe-se, acredita-se, denuncia-se ... mas não se comprova, não se apreende o como e o quando" (Codo \& Sampaio, 1995, p. 85).

Castro (2003), ao analisar a definição de psíquico utilizada por Codo e colaboradores em seus estudos (livros e artigos) sobre o sofrimento psíquico no trabalho, sustenta que, embora embasados no materialismo histórico, a definição de psíquico utilizada por tais autores permaneceu inalterada, relativamente à definição de psíquico freudiana ${ }^{1}$. Codo e colaboradores mantêmse, como sustenta Castro (2005), dentro das descrições freudianas do aparelho psíquico como determinado pelo dinamismo mental inconsciente, da consciência como representação e do sofrimento psíquico como doença ou disfunção do aparelho mental. ${ }^{2}$ Nesse sentido, a definição de psíquico de base freudiana utilizada pelo modelo de Dejours (1998) e a trabalhada por Codo e seus colaboradores para o estudo do sofrimento no trabalho não apresentam diferenças essenciais em termos de demarcação do objeto psicológico (Castro, 2003). Visto que, para o modelo psicanalítico de Dejours, a energia pulsional de origem sexual necessita ser reprimida e sublimada, sendo a organização de trabalho aquela que pode proporcionar uma satisfatória direção 
para as pulsões. Já no modelo de Codo e colaboradores, a energia afetiva (Codo, 1999), de origem inconsciente, tem no trabalho sua forma fundamental de expressão e, do mesmo modo que no modelo psicanalítico, quando tal energia encontra-se impedida de realizar-se neste âmbito essencial para a constituição humana, os mecanismos de defesa a fazem expressar-se em canais alternativos que podem ser, inclusive, a doença mental (Codo, Sampaio, \& Hitomi, 1992). Nesse sentido, as noções de mecanismos de defesa inconscientes, de consciência como representação, de mundo interior versus exterior, encontram-se presentes na definição de psíquico utilizada pelos autores brasileiros, fundamentados no materialismo histórico. Deste modo, afirmamos que o recurso a Marx e Leontiev não proporcionou uma definição de psíquico que respondesse às exigências técnicas e científicas postas pelo próprio Marx (1988), Marx e Engels (s.d.), Sève (1979), Vigotski (1996) e Politzer $(1969,1965)$. Em outros termos, não se respondeu, como sustenta Castro (2003), às reivindicações de uma ontologia que ultrapassasse a metafísica idealista e materialista e a uma antropologia que ultrapassasse o mentalismo em direção ao homem concreto. Contrariamente a isso, a definição de psíquico utilizada por Codo e colaboradores orientou-se a partir das metafísicas idealista e materialista, manteve-se dentro de uma noção de consciência como mundo interior e governada por forças inconscientes, o que fez os autores perderem o homem concreto e, por conseguinte, a possibilidade de descobrir e avançar no conhecimento dos acontecimentos psicológicos em suas relações com o trabalho.

Como foi possível, então, a Codo e colaboradores, partirem do materialismo histórico e chegarem a uma definição de psíquico compatível com o modelo freudiano que pretendiam superar (Codo, Sampaio, \& Hitomi, 1992)? Que caminhos percorreram? De que elementos teóricos se fizeram valer e como deles se utilizaram, de forma a chegarem a uma definição de psíquico que, em essência, apresenta-se com as mesmas características do modelo freudiano utilizado por Dejours? Com o objetivo de esclarecer tais questões é que este artigo foi escrito.

\section{Os Fundamentos Teóricos}

\section{Práxis versus Atividade}

A categoria Atividade de Leontiev mostra-se uma das principais fontes teóricas da definição de psíquico trabalhada por Codo e seus colaboradores. Nesse sentido, antes de propriamente esclarecer tal conceito e como ele foi apropriado pelos pesquisadores brasileiros, é instrutivo demarcar a diferença existente entre atividade e práxis, destacando a especificidade e centralidade que a segunda ocupa dentro do materialismo histórico, visto que Leontiev, como será mostrado no decorrer deste artigo, não realiza tal distinção. Fato este que acarretará desdobramentos fundamentais para que a definição de psíquico de Codo e colaboradores mantenha-se dentro das noções psicanalíticas freudianas.

Vasquez (1977) sustenta como o conceito de atividade caracteriza-se por sua amplidão, à medida que implica um agente na relação com uma matéria-prima que resulta em um produto. A natureza do agente e da matéria-prima, no âmbito da atividade, não é especificada e, nem tampouco, qual a espécie de atos que levam à formação do produto. $\mathrm{O}$ conceito de atividade aparece como sendo o oposto ao de passividade, caracterizandose como uma realização atual - e nunca potencial - de um conjunto de atos singulares que formam uma totalidade concreta. Ou seja, um processo total que culmina na modificação de uma matéria-prima em um produto (Vasquez, 1977). Nesse sentido, na demarcação do conceito de atividade cabem as atividades de um órgão do corpo humano, de um pássaro que faz seu ninho, de um cachorro que esconde seu osso etc.

Já no conceito de práxis, os atos para modificar a realidade material iniciam, e isto é essencial, com uma finalidade posta pelo sujeito que regula, de ponta a ponta, o processo de relação do homem com o mundo e que termina com um resultado efetivo e real para o sujeito. Como escreve Vasquez (1977, p.187):

Neste caso, os atos não só são determinados casualmente por um estado anterior que se verificou efetivamente - determinações do passado pelo presente - como também por algo que ainda não tem existência efetiva, e que, não obstante, determina e regula os diferentes atos antes de culminar num resultado real; ou seja, a determinação não vem só do passado, mas sim do futuro.

Deste modo, é possível afirmar que "toda ação verdadeiramente humana requer certa consciência de uma finalidade" (Vasquez, 1977, p. 187), e que toda atitude em relação aos condicionantes materiais e presentes caracteriza-se por superá-los em direção a uma realidade futura ainda inexistente e em função da qual a ação se realiza. De acordo com (Marx, 1988, p. 202):

$\mathrm{O}$ operário não se limita a fazer mudar as formas da matéria que lhe oferece a natureza, mas sim, ao mesmo tempo, realiza nela sua finalidade, finalidade que ele sabe que governa como uma lei às modalidades de sua atuação e a qual ele tem que sujeitar sua vontade.

Esta propriedade é que faz o ser humano não se encontrar em uma relação de exterioridade com seus diversos atos e produtos, como acontece quando se trata de um agente físico ou de um animal comum. Mas, ao contrário, numa relação de interioridade, à medida que 
seus atos e produtos estão em função de uma finalidade consciente e pessoal que o homem busca realizar como resultado de seu movimento na materialidade circundante. É a finalidade, dessa forma, que subordina e organiza os atos presentes e dá sentido aos produtos da práxis, de sorte que não considerar essa propriedade da realidade humana é reduzi-la a uma pura expressão exterior, é compreendê-la de fora, como uma soma de comportamentos condicionados unicamente do exterior.

Essa propriedade intencional da práxis, no entanto, não se reduz a uma pura antecipação ideal, na forma de um simples processo cognitivo, mas caracteriza-se como um projeto de algo que se quer, que se deseja (Vasquez, 1977), quer dizer, implica uma necessidade, uma falta ou desejo humano a serem satisfeitos, constitutivos da ação em todos seus momentos. Dessa forma, o que conduz o sujeito a agir é uma finalidade como negação do presente em direção a um futuro que quer que venha e não uma necessidade puramente orgânica ou, tampouco, uma ideia que só relaciona signos linguísticos. É certo que o corpo orgânico, tal como a cognição, compõe, sem dúvida, a estrutura da práxis, mas somente à medida que são ultrapassados por uma finalidade ou futuro como aquilo que lhes fornece significação. Um trabalhador cansado vive a dor de seus músculos como um momento de sua práxis, como necessidade de estar logo em casa, descansando em sua cama, com sua mulher, por exemplo. O corpo cansado é ultrapassado em direção a uma finalidade ou futuro que o sujeito quer que venha e somente desta maneira a fadiga humana torna-se compreensível.

É possível compreender, dentro desses limites, como o trabalho mostra-se uma das formas da práxis (Vasquez, 1977), à medida que o sujeito se apropria da natureza ou dos produtos da práxis de outrem e objetiva no meio do mundo certa finalidade ou projeto como um produto seu. Mas, da mesma forma, as relações com a sociedade, seja a prática política, as relações familiares etc., também manifestam formas específicas de práxis, que devem ser objeto de investigação, na busca de uma compreensão da totalidade de um homem concreto, para, assim, apreender as relações entre trabalho e sofrimento psíquico.

O conceito de práxis é também identificado por Kosik (1986), como central dentro da filosofia marxista, à medida que "a problemática da práxis, na filosofia materialista, nasce como resposta ao problema filosófico 'o que é o homem' e como é criada a sociedade" (Kosik, 1986, p. 201). Kosik esclarece como o conceito de práxis implica a compreensão da totalidade do homem concreto em suas relações com a realidade material, sendo impossível apreendê-la a partir do exterior, quer dizer, a partir de uma determinação externa que governaria de fora os atos humanos e lhes daria sentido:
A práxis não é uma determinação exterior do homem: uma máquina ou um cão não tem, nem conhecem a práxis. Uma máquina ou um animal não têm medo da morte, não sentem angústia diante do nada, nem alegria diante da beleza. (Kosik, 1986, p. 203).

A práxis implica, nesse sentido, o homem tendo no futuro a dimensão organizadora de sua existência individual ou coletiva (Kosik, 1986), subordinando o presente e o passado em função de uma finalidade material e concreta que demarca a práxis como uma ação temporal essencialmente humana: "O homem se submete ao (futuro) destino de escravo, ou luta pela (futura) condição de senhor apenas porque escolhe o presente em função do futuro e, portanto, configura o próprio presente com base nos projetos para o futuro" (Kosik, 1986, p.204).

Gramsci (1987), para quem o conceito de práxis mostra-se essencial para o materialismo histórico, corrobora essas constatações e sustenta que o sujeito humano é definido como síntese de suas relações materiais e sócio-históricas, em um devir concreto e material repleto de possibilidades oferecidas pelos outros homens e pelas condições materiais da sociedade:

dado que o homem é também o conjunto de suas relações de vida, pode-se medir quantitativamente a diferença entre o passado e o presente, já que é possível medir a proporção na qual o homem domina a natureza e o acaso. A possibilidade não é a realidade, mas é também ela, uma realidade: que o homem possa ou não possa fazer determinada coisa, isto tem importância na valorização daquilo que realmente se faz (Gramsci, 1987, p. 47).

Em suma, o conceito de práxis evidencia-se como um eixo central no materialismo histórico, sendo a partir dela, com todos seus componentes essenciais que a caracterizam, que a atividade prática humana é compreendida e a unidade subjetividade e objetividade encontra seus nexos com a histórica como produção humana. A partir destas duas definições iniciais, na sequência será exposto o conceito de atividade de Leontiev, base e ponto de partida para a definição de psíquico utilizada pelos autores brasileiros, vinculados ao materialismo histórico tratados no âmbito deste artigo.

Leontiev (1978a) não trabalha com o conceito de práxis, tratando e desenvolvendo exclusivamente o conceito de atividade. Ao tratar desse conceito, busca, sem dúvida, a demarcação entre a atividade imediata e a mediata ou, ainda, entre a atividade dos animais comuns e a atividade superior, propriamente humana, demonstrando para isso como se dá a evolução para as formas superiores de atividade, que implicam a aquisição e mediação da consciência. Mas é necessário interrogar: qual a implicação para a definição de psíquico o fato de se utilizar como uma das bases fundamentais um autor que não trabalha ou desenvolve o conceito de práxis? Ou 
ainda: como se relaciona o fato de se reduzir a noção de práxis à de atividade com o fato da definição de psíquico utilizada por Codo e seus colaboradores mostrar-se dentro das noções freudianas baseadas no determinismo inconsciente? (Castro, 2005). Para responder a essas questões, é necessário acompanhar, no pormenor, a elaboração do conceito de atividade desenvolvido por Leontiev, para, em seguida, analisar como esse conceito foi apropriado a partir de algumas noções da Psicologia Social Brasileira inspirada no materialismo histórico e, desta forma, encontrar o pano de fundo teórico dentro do qual está formada a definição de psíquico utilizada por Codo e seus colaboradores, bem como encontrar as ligações que tornam possíveis sua compatibilidade com o mentalismo freudiano.

\section{Atividade e Consciência em Leontiev}

Para Leontiev (1978a), o conceito de atividade tem a função de superar o esquema estímulo-reação e sua noção de passividade característica, para, então, unificar sujeito e objeto em uma síntese inseparável. O objetivo é compreender os acontecimentos psíquicos como resultado da atividade do sujeito frente à materialidade circundante e não mais abstraídos ou deslocados desta. Superar, então, a noção de psíquico como isolada da vida real e da noção de consciência como algo que permanece essencialmente a mesma no decorrer das transformações sociais e históricas é o objetivo que o conceito de atividade busca alcançar. É para as características desse conceito em Leontiev que primeiramente nos remeteremos.

A primeira característica da atividade é a de sempre existir como tendo um objeto que inicialmente dá-se como objeto material exterior, para, posteriormente, apresentar-se como interior ou reflexo psíquico (Leontiev, 1978b). Este objeto da atividade se caracteriza por ser aquilo que a orienta e regula, à medida que é nele que se objetivam determinadas necessidades que demandam satisfação. Nesse sentido, são as necessidades acopladas aos objetos que dirigem a atividade do indivíduo, não existindo, desse modo, necessidades desligadas de um objeto:

O encontro da necessidade com o objeto é um ato extraordinário que já foi observado por Darwin: Também alguns informes de Pavlov brindam provas sobre isto: Uznadzé se refere a ele como condição do surgimento da atitude e os etólogos modernos o descrevem brilhantemente. Este ato extraordinário é o de objetivação da necessidade, quer dizer, de seu 'recheio' com um conteúdo que se extrai do mundo circundante. (Leontiev, 1978b, p. 71)

O surgimento de necessidades humanas que não se encontram nos animais tem, para Leontiev, sua base fundamental neste encontro da necessidade com o objeto, sendo "esta circunstância a única que permite compreender a aparição de novas necessidades no homem" (Leontiev, 1978b, p. 71). Dessa forma, o objeto da atividade que acopla uma necessidade é identificado pelo autor russo como sendo o motivo da atividade. Motivo, no sentido de ser aquilo que impulsiona, encontrando-se, neste plano, os móveis da ação individual. Leontiev (1978a) fornece um tratamento teórico à questão da finalidade, sem, no entanto, abrir mão de seu princípio básico, qual seja, de ser a fusão objeto/necessidade o motivo ou móvel impulsionador de qualquer atuação humana. Nesse quadro, não é a finalidade que impulsiona a atividade prática do sujeito na relação com o mundo circundante, mas sim o próprio objeto como portador de necessidades, que condiciona o sujeito a agir no mundo circundante e objetivar um produto. A dimensão da finalidade, por sua vez, encontra seu lugar quando o autor explica que a atividade é realizada por um conjunto de meios e instrumentos:

É certo que a função de impulso se conserva plenamente no motivo. Outra coisa é a função da orientação: as ações que executam a atividade são impulsionadas pelo motivo, mas estão orientadas em direção a um fim. Suponhamos que o que impulsiona a atividade de um homem é o alimento: este é seu motivo. Não obstante, para satisfazer as necessidades da alimentação, os homens devem executar ações que não estão diretamente orientadas em direção à obtenção do alimento. (Leontiev, 1978b, p. 83).

É possível observar como a inclusão da dimensão da finalidade em Leontiev ganha um caráter instrumental, encontrando seu lugar no plano dos instrumentos e meios utilizados para satisfazer a necessidade posta pelo objeto às quais o indivíduo responde.

No entanto, esta macroestrutura da atividade (objeto/necessidade e meios/ instrumentos) está mediada pela consciência definida como reflexo psíquico (Leontiev, 1978b) construída através da relação direta e imediata do homem com a materialidade. A forma inicial do reflexo psíquico evolui para sua forma ideal - de signos linguísticos - que reflete não mais diretamente, mas idealmente a realidade material e social. Estes significados ou signos linguísticos, portanto, passam a ser os formadores primordiais da consciência humana: "Dito de outra maneira, nos significados está representada - transformada e comprimida em matéria de linguagem - a forma ideal da existência do mundo objetivo, de suas propriedades, de seus vínculos e relações descobertos pela prática social conjunta" (Leontiev, 1978b, p. 111).

A partir dessa definição da consciência humana como reflexo psíquico superior constituída por signos linguísticos, Leontiev (1978b) lhe acrescenta mais um conceito, qual seja, o de sentido pessoal. Este implica 
a singularização do significado que é compartilhado socialmente pelo sujeito, ou seja, o significado que existe socialmente e que passa a compor a consciência humana ganha um sentido individual, pessoal, tornando o reflexo psíquico algo singular, irredutível ao de outro indivíduo. Mas como, cabe perguntar, esse sentido pessoal passa a fazer parte da consciência? Neste ponto é importante retornar novamente à base da psicologia do autor russo, fundamentada no conceito de atividade e fazer uma retrospectiva do caminho percorrido e encontrar uma síntese para esta questão: o sentido pessoal é o "significado subjetivo e pessoal que tal significação tem para o sujeito" (Leontiev, 1978a, p. 96), e que forma a consciência como reflexo psíquico superior. Este depende da atividade que, por sua vez, se move em resposta a um objeto portador de uma necessidade, sendo, este último, o motivo que impulsiona às respostas individuais ao mundo circundante.

Compreende-se, então, que os motivos vão sendo refletidos na consciência e, com o decorrer da atividade, vão ganhando um lugar numa hierarquia de motivos que, por sua vez, passam a constituir a unidade da personalidade (Leontiev, 1978a). Este ponto, mais uma vez, permite compreender como o essencial da atividade é o objeto/necessidade que condiciona uma resposta, sendo a dimensão ontológica ${ }^{3}$ da finalidade ou do futuro um elemento que não participa dos móveis ou motivos que impulsionam a atividade. A dimensão temporal da práxis humana, dessa forma, fica perdida e a dialética subjetividade-objetividade que caracteriza o processo histórico individual ou coletivo resta mutilada. Afirmamos, desse modo, em acordo com Rey (1997), o caráter mecanicista do conceito de atividade de Leontiev, por mostrar-se baseado em um materialismo metafisico para o qual a realidade material sempre condiciona os móveis e motivos da ação humana ${ }^{4}$.

\section{Atividade e Consciência na perspectiva da Psicologia Social ${ }^{5}$}

Tendo esclarecido o conceito de atividade, passemos agora a considerar o modo como esse conceito é apropriado por Codo e colaboradores com recurso a certas noções da Psicologia Social inspirada no materialismo histórico. Primeiramente, é importante considerar o que ficou excluído do conceito de atividade para, em seguida, considerar o que foi apreendido do mesmo por Codo e seus colaboradores.

Um primeiro ponto a ser observado é o fato de Codo e colaboradores apoiarem-se nas noções presentes no livro Psicologia Social: o homem em movimento (1984), que se caracterizam por não considerar a demarcação entre práxis e atividade. Uma constatação, até certo ponto óbvia, à medida que se tem Leontiev como uma das bases teóricas principais, mas não menos importante de ser objeto de reflexão teórica, pois se refere à questão essencial de desconsiderar a dimensão temporal da finalidade ou do futuro como motivo e orientador da ação humana e, portanto, de todas as objetivações da subjetividade. Esse fato permite antecipar um problema crucial: à medida que a objetivação não é objetivação de uma finalidade ou projeto, ela se faz objetivação do quê? De uma força interior? De uma energia ou pulsão inconsciente? Ou seria a objetivação de uma resposta a um objeto que porta uma necessidade? Para o momento, é importante assinalar que o fato de se desconsiderar a dimensão temporal do futuro ou finalidade como motivo e organizador da atividade prática humana equivale a querer trabalhar em física com os fenômenos da teoria da relatividade, excluindo a potência $2 \underline{2}$ da fórmula $E=m$. $\mathrm{c}^{2}$. Isso quer dizer que a equação definidora das variáveis que permite compreender como a massa transforma-se em energia somente é compreensível com a variável velocidade da luz $\left(\mathrm{c}^{2}\right)$, caso contrário, já não expressa o fenômeno correspondente. Da mesma forma, excluir a dimensão da finalidade da práxis desfaz totalmente a equação que define os termos que tornam compreensível o homem concreto, tal como realizado pelo materialismo histórico, o que leva, consequentemente, à incompreensão das relações do homem com o trabalho e suas possibilidades de sofrimento.

Outro ponto excluído pela apropriação do conceito de atividade são as críticas que a própria Psicologia Soviética, a partir principalmente de década de 1970, realiza a respeito das debilidades que o mesmo conceito vinha há algumas décadas apresentando, impedindo o avanço científico. Chudnovsky (1982, citado por Rey, 1997, p. 77), um dos psicólogos soviéticos que passaram a verificar o problema, aborda a questão da seguinte maneira:

É impossível não afirmar que no curso de vários decênios, o problema da subjetividade em nossa ciência e na prática foi subvalorizado ... a necessidade de luta pela compreensão materialista do desenvolvimento social exigiu (e isso foi completamente correto) o acento na influência decisiva das forças produtivas e das relações de produção sobre a ideologia da sociedade e, através dela, no desenvolvimento da consciência e da personalidade do homem concreto. Lamentavelmente, estas posições que, em si, constituem um indiscutível pilar do marxismo, se absolutizaram e se converteram em um dogma.

Nepomnichaia (1977, citado por Rey, 1997), da mesma forma, ao sustentar como o conceito de atividade implicou uma concepção unilateral e limitada do objeto de estudo da Psicologia, atesta como, nesse âmbito, o pensamento, os processos sensoriais e a atividade foram separados da personalidade, ficando o próprio conceito 
de personalidade limitado ao motivo, e não incluindo nenhum outro aspecto do sujeito integral (Rey, 1997). Antes da década de 1970 inclusive, outro psicólogo soviético, Miasichev (1960, citado por Rey, 1997, p. 78), um dos fundadores da escola de Leningrado, mostrava-se já preocupado com o problema implicado pelo conceito de atividade:

Não obstante, a Psicologia soviética sofre de um subdesenvolvimento, e essencialmente sua lacuna radica em que o psíquico se examina preferencialmente como processo, mas seu portador, a personalidade, se estuda insuficientemente. A atividade se investiga separada de seu autor. O objeto (os processos psíquicos da atividade) se estuda sem o sujeito.

É possível notar que, desde a década de sessenta e, principalmente, na década de setenta, o conceito da atividade dentro da própria Psicologia Soviética já mostrava suas insuficiências num ponto essencial, qual seja, omitia o momento subjetivo da prática humana, só a apreendendo de fora e parcialmente por meio de suas reações aos objetos e aos condicionamentos materiais ou econômicos com suas objetivações nos produtos, empobrecendo, assim, a compreensão do objeto da ciência psicológica, e consequentemente, o conhecimento das relações do homem com o trabalho.

Considerando, então, que a apropriação do conceito de atividade realizada por Codo e colaboradores a partir da Psicologia Social Brasileira inspirada no materialismo histórico não atenta para a demarcação entre práxis e atividade, como também para as críticas às debilidades desse conceito realizadas pela Psicologia Soviética, como fica apropriado o conceito de atividade? E quais as condições de possibilidade desta apropriação permitir um avanço da Psicologia na direção pretendida por Codo e seus colaboradores para o estudo das relações entre sofrimento psíquico e trabalho?

Segundo Codo e colaboradores, pode-se observar que "o mérito de Leontiev, nada desprezível, foi o de explicitar e sistematizar a dupla relação homem-mundo como elemento de constituição da Psicologia" (Codo et al., 1992, p. 85). Nesse sentido, o conceito de atividade integra a demarcação do objeto da Psicologia à medida que "situa o homem na realidade objetiva" e "transforma esta realidade em uma forma de subjetividade" (Codo et al., 1992, p. 85). A fim de apreender melhor esse elogio a Leontiev, é instrutivo recorrer a algumas passagens de Silvia Lane que expressam a forma como Codo e colaboradores valeram-se do conceito de atividade de Leontiev na busca de sistematizar a dupla relação homem-mundo. Lane (1984a, p. 16), no intuito de alcançar o homem concreto, chama a atenção para dois fatos essenciais que serviram de ponto de apoio para Codo e colaboradores, quais sejam:
(1) a falsa dicotomia indivíduo/grupo, visto que o homem desde seu nascimento está inserido em grupos sociais e, (2) a aquisição da linguagem que preexiste ao indivíduo como código produzido historicamente pela sociedade (langue), mas que ele apreende na sua relação específica com outros indivíduos (parole). Se a língua traz em seu código, significados para o indivíduo, as palavras terão um sentido pessoal decorrente da relação entre pensamento e ação, mediadas pelos outros significados.

A apropriação realizada do conceito de atividade por intermédio dessas duas noções referidas por Silvia Lane fez com que Codo e colaboradores apreendessem do autor russo, por um lado, a indissociabilidade entre indivíduo e mundo social, característica da noção de atividade em geral e, por outro, a noção de consciência como reflexo psíquico superior, resultante da atividade mediada pela linguagem. Desse modo, a compreensão do homem concreto e de uma demarcação de psíquico compatível ficam situados dentro dos parâmetros da unidade indivíduo-social e da apropriação da linguagem. Quais os desdobramentos futuros que decorrem dessa posição? A resposta está na utilização das noções de representação e de identidade utilizada por Codo e seus colaboradores e que insere a sua definição de psíquico dentro do âmbito psicanalítico e psicopatológico freudiano. Tratemos com mais detalhes cada um destes pontos.

Lane (1986), ao explicar como o ser humano torna-se social, esclarece que a vida humana é uma vida em grupos, que implica a existência de regras, papéis sociais, relações de poder, ideologia e divisões de classe. É, então, no processo de relação social com os outros e com as condições históricas - ou seja, a partir da atividade - que o indivíduo apropria-se da linguagem e começa a relacionar os símbolos linguísticos presentes em seu entorno (Lane, 1986). A linguagem interiorizada, portanto, faz a mediação entre o indivíduo e os grupos, as classes, as forças ideológicas etc., o que permite a elaboração de representações sociais, caracterizadas "pelo sentido pessoal que atribuímos aos significados elaborados socialmente" (Lane, 1986, p. 34). Aqui, é importante ter presente o fundamento teórico de Leontiev, tal como é possível verificar na seguinte passagem: "Desta forma, os significados produzidos historicamente pelo grupo social adquirem, no âmbito do indivíduo, um sentido pessoal, ou seja, a palavra se relaciona com a realidade, com a própria vida e com os motivos de cada indivíduo" (Lane, 1984b, p. 34).

Com base na atividade, portanto, através da qual cada um se encontra em relação com grupos determinados e sofrendo a ação das ideologias e das forças econômicas, é que o indivíduo vai refletindo os significados sociais que, por sua vez, vão formar o conteúdo de sua consciência. Compreende-se, então, com base 
em Leontiev, a consciência como constituída por um conjunto de representações a partir da apropriação dos significados socialmente constituídos pelos grupos, face aos quais o indivíduo encontra-se em um processo de relação contínua. Conforme Lane (1986, p. 38):

Concluindo, para conhecermos as representações sociais de um indivíduo é necessário, através dos atos ilocutórios explícitos e implícitos, definirmos o lugar que ele ocupa em relação aos outros (os que se 'limitam' com ele), e através do discurso, como seu espaço se constitui nesta relação, enquanto a realidade subjetiva que se insere no real, socialmente representado e reproduzido em termos de 'todo mundo'.

Observa-se como essa apropriação do conceito de atividade de Leontiev conduz a uma noção de consciência como representação, ou seja, como conteúdos linguísticos que refletem a realidade exterior de uma forma ao mesmo tempo genérica - através dos significados - e individual - através do sentido pessoal, sendo, portanto, através do discurso ou dos atos de fala que se buscará interpretar o mundo subjetivo das representações sociais. O conjunto de representações sociais, nesse sentido, vão formar a identidade, na concepção formulada por Ciampa (1987), sendo esse conceito que agora será objeto de exposição, visto se constituir num outro elemento-chave das fontes teóricas da definição de psíquico utilizada por Codo e seus colaboradores.

\section{Identidade e Metamorfose em Ciampa}

Depois de haver partido do conceito de atividade de Leontiev em detrimento do conceito de práxis, ter concebido o primeiro como constituído pela dupla relação homem-mundo e utilizado da noção de consciência como representação, Codo e colaboradores passam a articular esses conceitos com a noção de Identidade, tal como definida por Ciampa (1987), para, assim, compor a base da definição de psíquico sobre a qual desenvolverão suas pesquisas no campo da saúde mental e trabalho.

A tese central defendida por Ciampa (1987, p. $133)$ é da identidade como metamorfose e sua construção implica a "predicação de uma atividade anterior", o que significa dizer que a identidade vem-a-ser, à medida que a atividade vai ganhando atributos que a qualificam. A atividade, desse modo, vai assumindo predicações por intermédio dos papéis sociais ou significados, adquirindo, assim, a característica de um personagem (Ciampa, 1987), e não simplesmente atributos gerais que os papéis sociais implicam. O conceito de identidade evidenciase, então, definido na forma de um personagem, ou seja, do indivíduo se tornando um representante de si mesmo perante os outros (Ciampa, 1987), da mesma forma como os outros comparecem, cada um, como representante de si em toda a trama social: "não só a identidade de um personagem constitui a de outro e vice-versa (o pai do filho e o filho do pai), como também, a identidade dos personagens constitui a do autor (tanto quanto a do autor constitui a dos personagens)" (Ciampa, 1987, p. 60).

Em relação ao conceito de atividade, Ciampa (1987) ressalta, principalmente, o seu caráter de movimento, de um vir-a-ser constante que se dá como um fazer do indivíduo no mundo, ou seja, como uma relação. É, portanto, neste plano da atividade que se realizam suas predicações e ocorrem as diferenciações e as identificações de cada indivíduo com os grupos sociais: "Sucessivamente, vamos nos diferenciando e nos igualando conforme os vários grupos sociais de que fazemos parte: brasileiro, igual a outros brasileiros, e diferente dos estrangeiros (nós os brasileiros somos, enquanto os estrangeiros são...)" (Ciampa, 1987, p. 63). Esse caráter de movimento dado à atividade vai implicar, portanto, um constante assumir e desfazer uma série infinita de personagens: é ser ao mesmo tempo uma multiplicidade de predicações que vêm a ser e deixam de ser constantemente, e, ao mesmo tempo, uma unidade que faz do indivíduo sempre um representante de si mesmo, ou seja: "por mais contraditório, por mais mutável que seja, sei que sou eu que sou assim, ou seja, sou uma unidade de contrários, sou uno na multiplicidade e na mudança" (Ciampa, 1987, p. 61).

Ao buscar instrumentos conceituais para fundamentar esta noção de devir e sustentar a identidade como metamorfose, Ciampa recorre a Hegel, especialmente à sua Lógica (Ciampa, 1987). A forma, então, de Ciampa apreender a dialética do processo histórico exposta pelo conceito de identidade desconsidera a crítica a respeito da dialética de Hegel empreendida por Marx em Grundrisse (Sève, 1979) e na Ideologia Alemã (s.d.), onde os princípios especulativos e abstratos, que consistem em reconhecer por toda e qualquer parte as determinações de uma lógica do espírito, são superados em função da necessidade concreta e científica de conhecer a lógica específica do objeto específico, ou seja, de conhecer a especificidade da práxis humana singular e coletiva. É neste sentido que se pode compreender a critica de D’Hondt (1987, p. 54):

Já não se pode ser mais hegeliano. Depois de Hegel a vida transformou-se, e também o pensamento da vida. A sua concepção de mundo sofreu o desgaste do tempo e foi submetida à crítica de Marx, destrutiva e ao mesmo tempo compreensiva, crítica essa inspirada numa dialética regenerada.

Recorrer, dessa forma, à dialética hegeliana como instrumento de apreensão do devir humano é, do ponto de vista científico, um equívoco, à medida que desconsidera a própria superação dialética que esta sofreu depois de Marx; e do ponto de vista histórico, um passo de volta 
para a metafísica idealista. Fato este que se evidencia na tentativa de Ciampa (1987) em seu ensaio de psicologia social, ao buscar apreender a trajetória de vida de Severina como uma particularidade em constante transformação dentro do devir de uma substância histórica. Pois tal como em Hegel, as contradições de um fenômeno (a particularidade da vida de Severina analisada por Ciampa) transformam-se em uma unidade no interior de um todo genérico e abstrato: a substância histórica. A lógica dialética para Ciampa torna-se dialógica, ou seja, uma contradição de ideias e representações, e a história humana uma entidade metafísica que conduz à perda da práxis singular e coletiva.

Seguindo o amparo de Hegel, o conceito de identidade aparece como a representação de um estarsendo no interior da substância histórica, ou seja, como uma concretização particular que se nega dentro da totalidade histórica, para afirmar-se como totalidade individual (Ciampa, 1987). Processo este que se dá através de interiorizações de personagens atribuídos socialmente (papéis sociais), consumando um devir constante de identificações, que não são outra coisa que a definição de predicação, já anteriormente explicada. O fundamental, nesse aspecto, é observar como essa relação entre o indivíduo como metamorfose de representações e o universal, como substância histórica, no âmbito desse idealismo hegeliano, somente ganha seu sentido pleno à medida que incorpora a noção de inconsciente (D'Hondt, 1987) como a força atuante em todas as individualidades e que realiza, através delas, os desígnios do espírito absoluto:

A história pode, pois, ser compreendida como a resultante dialética dos esforços individuais. Mas visto que obedece, enquanto obra global, a leis diferentes daquelas que regem as atividades parcelares, podemos também encará-la como a englobante suprema de todos os seres singulares, como o espírito mundial que habilmente os governa, deixando-os acreditar que se determinam livremente (D'Hondt, 1987, p. 27).

Nessa perspectiva metafísica, a história como substância englobante possui, em si própria, suas finalidades, que são realizadas pela totalidade das ações individuais "que inconscientemente trabalham para uma obra que não é sua" (D’Hondt, 1987, p. 27). É a partir desse horizonte metafísico que Marx é utilizado por Ciampa, à medida que é identificado com essa noção teleológica de Hegel, onde se compreende que o homem só existe como tal no final da história, ou seja, que somente no fim do processo histórico se realizam totalmente suas potencialidades: "do mesmo modo que, no esquema marxista da história, o homem só vem no final do que Marx denomina pré-história da sociedade humana - o espírito só aparece enquanto espírito no final da fenomenologia." (Ciampa, 1987, p. 175).
Nesse quadro metafísico em que, ao invés de se buscar avançar o trabalho de Marx, se retrocede para o idealismo anterior a ele, todas as predicações das atividades individuais que vão qualificando a identidade refletem um momento de pré-história da realização do sujeito: são predicações que negam o sujeito como sujeito. Esse processo, remetido ao singular, se caracteriza, para Ciampa, pela reposição constante de uma identidade pressuposta de uma forma imutável e atemporal. Assim, a identidade, que é metamorfose, é fixada e cristalizada como não metamorfose: é o "fetichismo da identidade" (Ciampa, 1987, p. 181). E como fundamento desta transformação da identidade fixada como não-metamorfose para sua forma metamorfose, Ciampa utiliza a noção de inconsciente como o empreendedor deste vir-a-ser, tal como acontece em Hegel no plano universal. É possível observar esse aspecto na passagem em que Ciampa faz referência a Stanislavsky, ao louvar o maior artista da natureza (Ciampa, 1987), qual seja, o subconsciente, como alguma coisa que interfere decisivamente na construção do personagem e na representação do ator:

Isso é criatividade verdadeira, vem de dentro, de emoções humanas, não teatrais ... Aí não tem lugar para raciocínios e análises. Não pode haver nenhuma dúvida quanto ao fato de que esta coisa inesperada ergueu-se do fundo manancial da natureza orgânica. O próprio ator é avassalado e cativado por ela. É transportado para um ponto que ultrapassa a sua consciência (Ciampa, 1987, p. 193).

É o inconsciente como esse fundo manancial que impulsiona a atividade humana a metamorfosear-se e a romper as barreiras das representações fixas e atemporais. É, a partir dessa base metafísica, que resultam os elogios de Ciampa à noção de espontaneidade de Jacob Moreno e à psicanálise, como ambas tendo muito a contribuir sobre o aspecto afetivo da atividade que leva a identidade a metamorfosear-se. Ou seja, é a raiz metafísica da noção de espontâneo criador, com suas fontes religiosas no Hassidismo e na Cabala judaica (Fonseca-Filho, 1980), fundada no dogma de uma "natureza primordial e imortal que contém todos os seres" (Moreno, 1978, p. 34), que Ciampa elogia como muito tendo a contribuir para compreender a afetividade humana que impulsiona toda metamorfose. Nesse aspecto, o idealismo alemão e a espontaneidade criadora mostram-se como dois lados da mesma postura metafísica que propõe: "substituir a relação vertical por uma horizontal, por um Deus próximo, o Deus presente. Deus está em todas as coisas do mundo, na Criação. As centelhas divinas do mundo são liberáveis. Quando acontece a liberação, o Deus latente aflora" (Fonseca Filho, 1980, p. 67). Portanto, é no âmbito desse quadro conceitual em que religião oriental e me- 
tafísica ocidental se encontram para substituir a práxis humana que Ciampa (1987) vai explicar a metamorfose da identidade como um aflorar libertário e espontâneo que se liberta das representações pressupostas por força do subconsciente ou da espontaneidade criadora que atua em cada um. É possível considerar, a esta altura, como o homem concreto, enquanto sujeito que organiza seu presente e supera seu passado em função de uma finalidade futura para a qual se projeta, fica anulado e perdido entre o materialismo mecanicista de Leontiev e o idealismo de Hegel e de Moreno.

Como mais um elemento de base em relação ao conceito de identidade como metamorfose, Ciampa (1987) utiliza-se de Habermas, no que diz respeito à definição de Identidade do Eu do autor alemão. É instrutivo considerar as noções implicadas na definição de Identidade do Eu de Habermas, pois permitirá compreender a função do elogio de Ciampa à psicanálise e, desse modo, compreender como Codo e colaboradores, apesar de partirem do materialismo histórico, da crítica à especulação e exigirem uma outra definição de psíquico que não fosse a freudiana, não alcançam seus objetivos.

Habermas (1983) busca formular o conceito de Identidade do Eu à luz de sua "teoria do agir comunicativo" (Habermas, 1983, p. 65). Nesta, o autor usa como núcleo central a noção de mundo da vida, espaço onde se desenvolve a subjetividade, definida nos seguintes termos:

O lugar transcendental onde o que fala e o que ouve se encontram, onde eles podem reciprocamente colocar a pretensão de que suas declarações se adequam ao mundo e onde eles podem criticar e confirmar a validade de seus intentos, solucionar seus desacordos, e chegar a um acordo (Antunes, 1999, p. 147).

A edificação das identidades, para Habermas, realiza-se nesta esfera do mundo da vida, noção tirada da fenomenologia (Antunes, 1999), em particular, do idealismo fenomenológico de Husserl e de sua noção de intersubjetividade transcendental (Fragata, 1985), para a qual as relações humanas não são mediadas pelas condições materiais, mas restritas a trocas simbólicas e contradições no plano do discurso, desimplicadas com a produção material da vida. A partir dessa noção de identidade, Habermas explica seu processo evolutivo por etapas ou níveis, que vão sobrepondo-se e servindo de base para os níveis seguintes. São níveis de evoluções do universo simbólico do indivíduo, onde cada um desses níveis simbólicos ou cognitivos correspondem a determinadas estruturas do agir comunicativo (Habermas, 1983). O primeiro nível implica uma correspondência ao outro, o segundo numa correspondência aos papéis sociais e o terceiro implica a capacidade de compreender, interpretar e aplicar normas reflexivas cada vez mais abstratas para poder interagir intersubjetivamente
(Habermas, 1983). De sorte que a identidade do Eu se desenvolve a partir do universo do discurso intersubjetivo, evoluindo de um nível simbólico para o outro, até alcançar, no adulto, uma organização cognitiva particular baseada em princípios ou modos universais de agir (Habermas, 1983).

Importante compreender que todo este processo de formação da identidade do eu em Habermas ocorre no plano da consciência, da elaboração consciente do nível interativo, ou seja, no plano do juízo, que corresponde a uma determinada "competência interativa" (Habermas, 1983, p. 70). Assim, a construção da identidade do eu vai abranger o aspecto cognitivo, consciente, e não o aspecto motivacional, afetivo ou inconsciente, que se refere aos destinos das pulsões (Habermas, 1983). Habermas, inclusive, comenta o fato de que, quando acontece alguma debilidade nesse plano consciente, existem os mecanismos de defesa inconscientes para as situações em que se deseja evitar a elaboração consciente dos conflitos. Observa-se, desse modo, como a noção de identidade compatibiliza-se com o arcabouço conceitual psicanalítico, respaldando a noção de psíquico de Freud (Heck, 1987) e esforçando-se para apresentá-la como produção simbólica no interior da cultura:

As necessidades (pulsões) já se dão interpretadas em termos de linguagem, simbolicamente fixadas; a herança natural (impulsos desprovidos de qualquer especialização) só determinam as condições iniciais da reprodução humana, mas os meios de reprodução societária implicam na auto-conservação, reproduzir sua vida em condições culturais (Habermas, 1987, p. 299).

Com o que foi exposto, é possível compreender que os aspectos afetivos que impulsionam a identidade a metamorfosear-se são de ordem inconsciente, sejam estes o espírito hegeliano, o fundo manancial de vida de Stanislavsky, o espontâneo criador ou as pulsões freudianas. Impossível não notar como Codo e seus colaboradores, ao partirem do conceito de atividade para fundar uma base social para o psiquismo, utilizarem-se da noção de consciência como representação e, por fim, articularem ambos com a noção de identidade que se metamorfoseia inconscientemente, fazem um retorno à metafísica e ao idealismo, resultando, assim, uma definição de psíquico híbrida, um amálgama composto pelo materialismo mecanicista de Leontiev, que os autores não souberam superar, e pelo idealismo do qual não conseguiram desprender-se. Verifica-se, desse modo, uma contradição a resolver entre, por um lado, a atividade que responde a uma necessidade advinda do objeto exterior, mas, por outro, a atividade que responde a uma força interior inconsciente que transforma a identidade. Em outros termos, de um lado, as bases da definição de psíquico utilizada por Codo e colaboradores mostram-se baseadas no materialismo não dialético de Pavlov ou 
na evolução natural (Leontiev, 1978b), e, de outro, no espiritualismo e no inconsciente. Necessita-se, em função disso, retomar e desenvolver a definição de práxis e ultrapassar esta circularidade que do materialismo metafísico retorna ao idealismo, perdendo, assim, o caminho para fazer avançar a ciência e em direção à apreensão da práxis histórica no estudo das relações entre trabalho e sofrimento psíquico.

\section{Considerações Finais}

Concordamos com Codo, Sampaio e Hitomi quando afirmam que (1992, p. 82) "a história tem demonstrado que uma ciência só avança quando logra uma definição operacional capaz de impulsionar novas descobertas. Assim, faz sentido a discussão metateórica, revendo e posicionando sempre o universo científico e suas categorias de análise". Neste sentido, é na preocupação científica com o avanço do conhecimento sobre as relações entre trabalho e sofrimento psíquico que se situa a presente discussão teórica, buscando identificar debilidades e sustentar uma hipótese para superá-las.

No que diz respeito às debilidades teóricas, a primeira delas refere-se ao conceito de atividade de Leontiev. Sem dúvida, a preocupação de Leontiev, como também a de Codo e seus colaboradores em articular subjetividade e objetividade, é fundamental para o avanço da ciência psicológica por buscar situar o fenômeno psíquico no interior do plano social e histórico. Porém, buscou-se no decorrer deste artigo mostrar que: ou ultrapassa-se o conceito de atividade para o conceito de práxis e, assim, descobre-se a dimensão temporalizante da práxis humana como fundamento de uma antropologia e de uma outra definição de psíquico, ou fica-se restrito a compreender o motivo da atividade humana no âmbito de um materialismo mecanicista que tem suas bases na evolução natural e na etologia.

Essa limitação teórica conduziu Codo e seus colaboradores a articular o conceito de atividade com os conceitos de consciência como representação e de identidade como personagem, para, então, conseguir compor uma definição de psíquico que pudesse lograrse operacional às novas descobertas no campo da saúde mental e trabalho. Porém, pretendeu-se sustentar como a utilização desses conceitos se desviaram da perspectiva da práxis e do materialismo histórico, retornando às posições metafísicas precedentes caracterizadas pelo idealismo hegeliano e por forças inconscientes que somente mudaram de nome.

As bases da noção de psíquico trabalhada por Codo e colaboradores encontram-se, portanto, dentro do domínio da consciência como representação, determinada por forças inconscientes que determinam a metamorfose da identidade e pelos mecanismos de defesa que buscam preservar a integridade do ego, tal como sustenta a posição freudiana. Encontram-se, nesse aspecto, fora do domínio da práxis, do homem concreto e do materialismo histórico como exigido por Marx, Politzer, Vigotski e Sève como fundamento de uma perspectiva dialética do homem concreto e de sua historicidade.

De sorte que, ao buscar as bases da noção de psíquico no conceito de atividade de Leontiev, bem como ao apropriarem-se das noções de consciência e identidade da Psicologia Social de inspiração materialista histórica, Codo e colaboradores não chegaram a outra definição de psíquico do que à perspectiva freudiana. Desconsiderando o conceito de práxis para fazerem uso do conceito de atividade, e utilizando das noções de consciência como representação e de identidade como personagem, constituíram uma definição de psíquico cindida entre duas metafísicas: a materialista e a idealista. Esta incursão, portanto, sobre as bases da definição de psíquico utilizada por Codo e colaboradores, revelou que o recurso desses autores às noções de atividade, de consciência como representação e de identidade com metamorfose não os fez lograr os objetivos que pretendiam, ou seja, uma nova orientação de homem e do objeto psicológico para superar as lacunas referidas no campo da saúde mental e trabalho.

\section{Notas}

1 Esta análise da definição de psíquico de Codo e colaboradores foi realizada na dissertação de mestrado de Castro (2001) e abrangeu as obras do autor e seus colaboradores publicadas até o ano de 2001. No entanto, os trabalhos publicados e organizados pelo autor posteriormente permitem afirmar a validade destas conclusões, principalmente àqueles contidos no livro O trabalho enlouquece?: um encontro entre a clínica e o trabalho (Codo, 2004), no qual o recurso à abordagem psicanalítica encontra-se explicitada.

2 Uma apresentação, análise e discussão clara e detalhada das obras e da definição de psíquico utilizada por Codo e Colaboradores está exposta no artigo "A problemática da definição de psíquico nos estudos de Wanderley Codo e colaboradores sobre o sofrimento psíquico e trabalho" (Castro, 2003).

3 Ontológica aqui no sentido dado por Lukács (1976) em "Per l'Ontologia dell'Essere Sociale”, vol. I, Roma, Editori Riuniti, onde o "pôr teleológico" é uma característica ontológica de toda ação humana e que vai constituir sua historicidade. Obra que está sintetizada em suas teses principais por Antunes (1999) em Os Sentidos do Trabalho.

4 Considerando, conforme Sartre (1985, p. 39) que, "há duas maneiras de cair no idealismo: uma consiste em dissolver o real na subjetividade, a outra em negar toda subjetividade em benefício da objetividade", é a esta segunda maneira que estamos aqui a nos referir quando atestamos o caráter mecanicista e metafísico do conceito de atividade de Leontiev.

Importante considerar que, no âmbito deste artigo, está-se considerando unicamente certas noções da Psicologia Social Brasileira que serviram de fonte teórica para o desenvolvimento da definição de psíquico utilizada por Codo e colaboradores. 


\section{Referências}

Antunes, R. (1999). Os sentidos do trabalho. São Paulo: Boitempo.

Castro, F. G. (2001). A problemática da definição de psíquico nos estudos de Wanderley Codo e colaboradores sobre o sofrimento psíquico e trabalho. Dissertação de Mestrado, Programa de Pós-Graduação em Psicologia, Universidade Federal de Santa Catarina, Florianópolis.

Castro, F. G. (2003). A problemática da definição de psíquico nos estudos de Wanderley Codo e colaboradores sobre o sofrimento psíquico e trabalho. Psicologia: Organizações e Trabalho, 3(1), 111-133.

Castro, F. G. (2005). Sofrimento psíquico no trabalho: limitações e avanços a respeito do problema. Plural, ano 11, 14, 34-47.

Ciampa, A. C. (1987). A estória do Severino e a história de Severina: um ensaio de psicologia social. São Paulo: Brasiliense.

Codo, W. (Coord.). (1999). Educação, carinho e trabalho. Petrópolis, RJ: Vozes.

Codo, W. (Org.). (2004). O trabalho enlouquece? Um encontro entre a clinica e o trabalho. Petrópolis, RJ, Vozes.

Codo, W. \& Lane, S. (Orgs.). (1984). Psicologia Social: o homem em movimento. São Paulo: Brasiliense.

Codo, W. \& Sampaio, J. J. (Orgs.). (1995). Sofrimento psíquico nas organizações. Petrópolis, RJ: Vozes.

Codo, W., Sampaio, J. J., \& Hitomi, A. H. (1992). Individuo, trabalho e sofrimento. Petrópolis, RJ: Vozes.

Dejours, C. (1998). A loucura do trabalho. São Paulo: Atlas.

D'Hondt, J. (1987). Hegel. Lisboa: Edições 70.

Fonseca Filho, J. (1980). Psicodrama da loucura: correlações entre Buber e Moreno. São Paulo: Ágora.

Fragata, J. (1985). A fenomenologia de Husserl: como fundamento para a filosofia. Braga: Livraria Cruz/Faculdade de Filosofia.

Gramsci, A. (1987). Concepção dialética da história. Rio de Janeiro: Civilização Brasileira.

Habermas, J. (1983). Para a reconstrução do materialismo histórico. São Paulo: Brasiliense.

Habermas, J. (1987). Conhecimento e interesse. Rio de Janeiro: Guanabara.

Heck, J. N. (1987). Introdução. In J. Habermas. Conhecimento e interesse. Rio de Janeiro: Guanabara.

Kosik, K. (1986). Dialética do concreto. Rio de Janeiro: Paz e Terra.

Lane, S. T. M. (1984a). A psicologia social: uma nova concepção de homem para a psicologia. In W. Codo \& S. Lane (Orgs.), Psicologia social: o homem em movimento (pp. 10-19). São Paulo: Brasiliense.

Lane, S. T. M. (1984b). Linguagem, pensamento e representações socais. In: W. Codo \& S. Lane (Orgs.), Psicologia social: o homem em movimento (pp. 32-39). São Paulo: Brasiliense.
Lane, S. T. M. (1986). O que é psicologia social. São Paulo: Brasiliense.

Leontiev, A. (1978a). Actividad, conciencia y personalidad. Buenos Aires, BA: Ediciones ciencias del hombre.

Leontiev, A. (1978b). O desenvolvimento do psiquismo. Lisboa: Horizonte universitário.

Lima, M. E. (2002). Esboço de uma crítica à especulação no campo da saúde mental e trabalho. In M. G. Jacques \& W. Codo (Eds.), Saúde mental \& trabalho: leituras (pp. 50-81). Petrópolis, RJ: Vozes.

Marx, K. (1988). O capital. Rio de Janeiro: Bertrand-Brasil.

Marx, K. \& Engels, F. (s.d.). A ideologia alemã (2 vol.). Lisboa: Editorial Presença.

Moreno, J. (1978). Teatro del la espontaneidad. Buenos Aires, BA: Ciencias del hombre.

Politzer, G. (1965). Psicologia concreta. Buenos Aires, BA: Alvarez S.R.L.

Politzer, G. (1969). Critica de los fundamentos de la psicologia. Barcelona: Martines Roca.

Rey, G. F. (1997). Epistemología cualitativa y subjetividad. São Paulo: Educ.

Sartre, J-P. (1985). Critique de la raison dialectique, Tome 1: Théorie des ensembles pratiques. Paris: Gallimard.

Seligmann-Silva, E. (1996). Psicopatologia do trabalho. In M. Mendes (Org.), Patologias do trabalho (pp. 289-310). São Paulo: Ateneu.

Sève, L. (1979). Marxismo e teoria da personalidade (3 vol.). Lisboa: Horizonte Universitário.

Vasquez, A. S. (1977). Filosofia da práxis. Rio de Janeiro: Paz \& Terra.

Vigotski, L. S. (1996). O significado histórico da crise na psicologia: uma investigação metodológica. In L. S. Vigostki. Teoria e método em psicologia. São Paulo: Martins Fontes.

Fernando G. Castro é Psicólogo e Psicoterapeuta, Mestre em Psicologia e atual doutorando do Programa de Pós-Graduação em Psicologia da Universidade Federal de Santa Catarina. Endereço para correspondência: Rua Hipólito Machado, 96, Bairro Santo Antônio de Lisboa, Florianópolis, SC.

CEP: $88050-480$

E-mail: feir@uol.com.br

\section{Materialismo Histórico e definição de Psíquico \\ Fernando G. Castro}

Recebido: 25/02/2008

$1^{\mathrm{a}}$ revisão: $12 / 07 / 2008$

$2^{a}$ revisão: 06/10/2008

Aceite final: 31/10/2008 